\title{
Apert Syndrome
}

\author{
KG Mostafa1, CH Rasul2, NN Baruri3, SM Rahman4
}

\begin{abstract}
Summary
Apert syndrome is a rare autosomal dominant malformation. In the recent past we encountered a boy of 16 months with fusion of both fingers and toes, dysmorphic facial features presenting with cough and respiratory distress in Khulna Medical College hospital. Considering the general paucity of cases of acrocephalosyndactyly in the Bangladeshi literature, this case demands reporting. Careful evaluation is necessary in a doubtful case to optimize the treatment.
\end{abstract}

\section{Introduction}

Apert syndrome (acrocephalosyndactyly) is a rare congenital disorder characterized by craniosynostosis, midfacial hypoplasia, symmetrical syndactyly of the hands and feet and other systemic malformations.1. The condition was first reported by wheaton in 1894 . Subsequently in 1906, Apert summarized nine cases and since then his name has been associated with acrocephalo-syndacyly. In 1920 Park and Powers published an exceptional essay on this entity.2 In 1974, about 207 cases had been reported in the world literature. 3 This disorder occurs in about 1 in every 65000 life birth.2

Once suspected the diagnosis can be confirmed by DNA analysis for the mutation in the FGFR2 gene, which together accounts for $98 \%$ of the Apert cases. Though the mutation is autosomal dominant, the vast majority of cases of Apert are due to new mutation. The incidence of FGFR2 mutation increases exponentially with parental age, probably due to an increase in the frequency of these mutations and a selective advantage in the male germline.4 Different mutation in the same gene causes cruzon syndrome as well as Pfeiffer syndrome. The recurrence risk for the unaffected parents of a child with Apert syndrome is negligible, whereas the recurrence risk for affected individual is $50 \% .2$

Mental retardation is considered usual for the patient with Apert syndrome and may be due to brain malformations, high intracranial pressure or family environment. Apert syndrome answers for $4.5 \%$ of all craniosynostosis.5 Early surgical treatment of both cranial and facial malformations reduces the deleterious effects of increasing intracranial pressure on nervous structure, therefore leading to a harmonious development of cranioencephalic set, minimizing the cognitive loss. The timing for surgical intervention is to perform before first year of life. 6

Apert syndrome has been diagnosed early in pregnancies in affected families, using variety of modalities, including fetoscopy, sonography and more
Bang Med J (Khulna) 2011; 44 : 25-27

recently, molecular analysis.7 Central nervous system (CNS) anomalies in patients who have Apert syndrome have been previously documented. Awareness of the fact that CNS abnormalities including borderline ventriculomegaly and agenesis of corpus callosum (ACC) can be features of Apert syndrome will increase opportunities for prenatal diagnosis in the second trimester.

\section{Case report}

Rifat a boy of 1 year 4 months old coming from Koyra, Khulna got admitted in Khulna Medical College Hospital on 8th January, 2011, with the complaints of cough and respiratory distress for last 5 days. His mother complained of fusion of both fingers and toes with dysmorphic facial features since birth. The child was born with attached fingers and toes, protruded eyeball and cleft plate. The child suddenly developed respiratory distress which was associated with cough and rhinorrhoea, aggravated by cold or very hot weather. These episodes occurred several times. There is no history of consanguinity of marriage.

His mother had syndactyly of right hand which was separated by operation at her 7 years of age. He was delivered pervaginally without any complications. He was fed exclusive breast feeding upto six months, then weaned with family foods. He established neck control at 4 months of age, sitting at 6 months of age, standing with support at 10 months of age and started bubbling at 1 year of age. He is fully immunized and treated several times for upper respiratory tract infection. The child was found ill-looking, brachycephalic along with exophthalmos, hyper-telorism, flat maxilla, low set ear, beaking of nose, small occipitofrontal circumference $(44 \mathrm{~cm})$ (Fig-1), cleft palate, symmetrical syndactyly of both hands and feet (Fig-2).

1. Khan Golam Mostafa MD, Assistant Professor of Paediatrics, Khulna Medical College, Khulna.

2. Choudhury Habibur Rasul FRCP, Professor of Paediatrics, Khulna Medical College, Khulna.

3. Nitya Nanda Baruri DCH, Assistant Professor of Paediatrics, Khulna Medical College, Khulna.

4. Sk Masiur Rahman MBBS, Assistant Registrar of Paediatrics, Khulna Medical College Hospital, Khulna. 


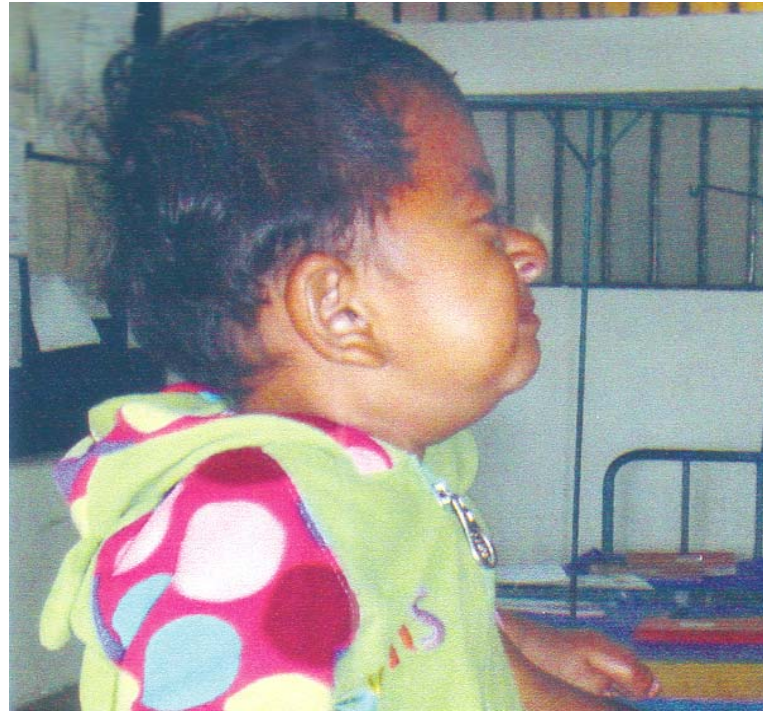

Fig-1 : Beaking of nose \& small occipitofrontal circumference

Examination of respiratory system revealed vesicular breath sound with wheeze and crepitation in both lung fields. Other systemic examination findings were normal.

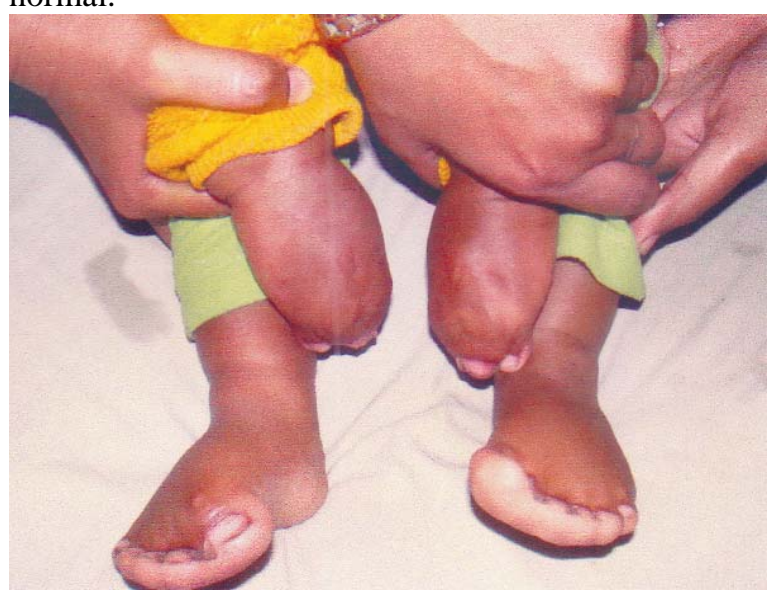

Fig-2 : Symmetrical syndactyly of both hands and feet

Clinical diagnosis was Apert syndrome with wheezy child and differential diagnosis was crouzon's syndrome. Routine investigation showed microcytic hypochromic anaemia, X-ray chest was suggestive of pneumonitis, X-ray hands and feet showed syndactyly of hands and feet and polydactyly of feet. CT scan of brain revealed diffuse cortical atrophy, ocular hypertelorism, bilateral proptosis. Ultrasonography and Echocardiography was normal.

\section{Discussion}

Apert syndrome was named after a French physician E. Apert, who described, in 1906, a relatively uncommon craniofacial anomaly.9 The condition may be inherited with a frequency of $50 \%$ in the offspring of an affected parents or more commonly develops as a result of spontaneous new mutation. In our case, mother had syndactyly.

Prenatal sonographic diagnosis of Apert syndrome relies upon detection of the triad of abnormal cranial shape, midfacial hypoplasia and bilateral syndactyly of hands and feet. Targeted ultrasonography in families at risk has identified mitten hands as early as 16-17 weeks gestation.10

A deformity of the osseous system is most conspicuous features of the syndrome of acrocephalosyndactyly. It is recognizable at birth and characteristically affects the head and extremites. 3 In our case, however the deformities were noticed at birth. The domains of abnormalities found in Apert syndrome are- growth abnormalities, performance/ cognition, central nervous system, craniofacial, limbs, skin and others.2 Occasional abnormalities are short humerus, pyloric stenosis, ventricular septal defects, polycystic kidney, hydronephrosis, vaginal atresia and diaphragmatic hernia etc. 2

Some mental impairment is present in almost every case, but its true incidence is not known. Most cases show no visceral abnormalities. Various classification of acrocephalosyndactyly like, vogt's, moth's. Waarden burgs and pfeiffers, depends upon the type and degree of syndactyly present. Syndactyly is one of the distinguishing features between Apert and crouzon's syndrome.

All patient's have progressive calcification and fusion of the bones of the hands, feet and cervical spine.11 Babies with Apert syndrome should also be considered at risk for obstruction to breaths at least during sleep.12 Commonly associated features include cardiac anomalies, visual and hearing defects, cleft plate and varying degree of acne. Moderate to severe acne at puberty and had lesion on the arms and forearms in addition to commonly affected sites and usually resistant to treatment.13 Skin, eyes and hair may show pigmentary dilution. There is reduced intellectual capacity in some individual. Cerebral cortical atrophy with dilation of lateral ventricle may lead to mental abnormality. 6

Early surgery for craniosynostosis is indicated where there is evidence of increased intracranial pressure. Moderate to severe language difficulties occur frequently. Clinically significant social problem and social withdrawal are common.2 Treatment involves multidisciplinary team work including craniofacial surgeon, neurosurgeon, pediatrician, speech therapist, pathologist and an orthodontist.

In conclusion, the quality of family environment and the parent's education level are the most signicant factors directly involved in the mental development of the patients with Apert syndrome.

\section{Reference}

1. Apert E, Del acro cephalosyndactyly, Bull Mem Soc Med Hop 1906; 21: 1310-30.

2. Jones KL, SMITH'S Recognizable Patterns of Human Malformation: Craniosynostosis syndrome, Apet syndrome. 6th edition, Philadelphia: WB SAUNDERS, 2006, 474-77. 
3. Punwani DV, Puropritv, train SF, Kunta NB. Apert syndrome - a type of acrocephalosyndactyly - a case report. J postgrad Med 1979; 25:109-11.

4. Glaser RL, Broman KW, Schulman RL, Eskenazi B, Wyrobek AJ. Jabs EW. The paternal age effect in Apert syndrome is due, in part, to the increased frequency of mutation in sperm. Am J Hum Genet 2003; 73: 939947.

5. Cohen MMJ, Kreiborg S, Lammer EJ, et al. Birth prevalence study of the Apert syndrome. AMJ Med Genet 1992; 42: 655-59.

6. Renier D, Amand E, Cinelli G, Sebag G, Zerah M, Marchac D. Prognosis for mental function in Apert syndrome. J Neurosurg. 1996; 85: 66-72.

7. Chan CT, Thorgood P. Pleotropic features of syndromic craniosynostosis corrected with differential expression of fibroblast growth factor receptors $1 \& 2$ during human craniofacial development. Pediatr Res. 1999; 45: 46-53.

8. Cohen MM. Kreiborgs. The central nervous system in the Apert syndrome. AMJ Med Genet. 1990; 35: 36-45.
9. Harper JI. Genetics and genodermatoses. In: Champion RH, Burton JL, Burns D, Breathnach SM (editors): Rook/ Wilkinson/ Ebling, Text book of dermatology. 6th ed. Oxford: Black Well Science; 1998: 425-6.

10. Narayan H, Scott IV. Prenatal ultrasound diagnosis of Apert's syndrome. Prenat Diagn. 1991; 10: 187-92.

11. Kins man Sl and Johnston MV. Craniosynostosis in congenital anomalies of central nervous system. In: Kliegman RM, Behrman RE, Jenson HB, Stanton BF (Editors). Nelson Text Book of Pediatrics. 18th Edition Vo1.2 Philadelphia: Elseiver, Saunder's, 2007, 2455-6

12. Helm's P, Henderson J, Nasopharyngeal abnor-malities In congenital abnormalities of respiratory disorder. In: Melntosh N, Helms PJ, Smyth RL (editors). Forfar \& Arneil's text book of pediatrics 6th edition, Edinburgh Churchill living stone, 2003; 18: 787-88.

13. Solomon LM, Fretzin D, Pruzansky S. Pilosebaceous abnormalities in Apert syndrome. Arch Dermatol 1970; 102: 381-5. 